\title{
New Year: New editors and new challenges
}

\section{Ano Novo: Renovação da editoria e novos desafios}

$T^{2}$

he Brazilian Journal of Physical Therapy (BJPH) has consolidated its course, continuously reaching for new

goals. Its achievements are the result of intense work and commitment on the part of many professionals who, under the guidance of competent chief editors in line with the Journal's objectives, conquered the status it holds today as the main periodical in its field, not only in Brazil, but also in Latin America.

The BJPT editorial team, which is being reformulated in 2010, will continue to encourage the participation of new researchers. It was in this context that we were nominated and elected at an editorial team meeting. As a group, we wish to embrace this honorable and challenging academic task with the best of our efforts, so that we can live up to the standards of excellence set by the editorial teams that preceded us.

The renewal of the BJPT editors creates new challenges that include maintaining the important conquests made by the previous editorial teams and continuing to be indexed in Scielo, CINAHL, Periódica, SCOPUS, EMCare, SciSearch and ISI/JCR. Above all, we hope to attain international recognition through the much awaited indexing in Medline in 2010. Based on the definition of "impact factor" put forward by the Journal Citation Report (JCR), we will also make every effort to ensure that the BJPT stays on its ascending path, pursuing actions to reinforce and increment its impact factor.

Another important challenge for the new Editorial Team involves its financial stability. The BJPT currently relies on funding from partners such as CREFITO-3, UNINOVE and projects developed alongside CNPq, FAPESP, and FAPEMIG. We hope to carry on with the support of UFSCar and UFMG, which have offered the Journal an enormous contribution, and with the support of all area editors, advisors, ad hoc counselors and the entire BJPT administrative staff.

It is important to highlight that, from now on, we will also count on the collaboration of USP. We strongly believe that the success of the BJPT reflects the success achieved by the area of physical therapy as a whole, particularly as regards its high-level scientific production, which is the result of the work developed by many competent and committed groups from several parts of Brazil. 
It is in this spirit of excellence and reliance on the commitment of all partners that this new team of editors takes over the BJPT with the resolve to continue growing and advancing toward the proposed goals, thus ensuring that the BJPT remains an important scientific publication in the areas of physical therapy and rehabilitation sciences.

Aparecida Maria Catai

Débora Bevilaqua Grossi

Marisa Cota Mancini 